\title{
The Impact of Institutional Power on Higher Degree Research Supervision: Implications for the Quality of Doctoral Outcomes
}

\author{
Dr. Angele Jones, Professor Eddie Blass*
}

Torrens University Australia, Australia

Copyright $\mathrm{O} 2019$ by authors, all rights reserved. Authors agree that this article remains permanently open access under the terms of the Creative Commons Attribution License 4.0 International License

\begin{abstract}
This paper examines the impact of power in the supervision process as experienced by the $\mathrm{PhD}$ students, the institutional influence upon this, and implications for the quality of the doctoral outcome. This research paper is based on findings of a larger, recently completed $\mathrm{PhD}$ with the aim to develop a participant-driven theory of the lived experience of being a $\mathrm{PhD}$ student. This was done by analyzing the reported experiences of $23 \mathrm{PhD}$ students in various disciplines and stages of their $\mathrm{PhD}$ studying at Australian Universities over a period of 12 months. Participants were given the freedom to choose and prioritize the experiences to report on and how they reported on them. Core to the supervision findings was the issue of power and how institutional influences distort the power relationship between the supervisor and the supervisee. Adopting French and Raven's (1959) Bases of Social Power, the institutional power sources that play on the $\mathrm{PhD}$ candidate are enacted through 'actors' in the institutional process including the supervisor who are presented. The findings support the need for institutions to systematically review their practices to meet their duty of care to their $\mathrm{PhD}$ students to provide high quality HDR supervision and improve doctoral outcomes. This research addresses a gap in contemporary supervision literature by addressing the impact of institutional power and institutional practices on the academic supervisor and how these play out in the utilization of power on and over the $\mathrm{PhD}$ student and the doctoral outcome.
\end{abstract}

Keywords $\mathrm{PhD}$, Supervision, Institutional Power, Supervisor Relationship, PhD Outcomes

\section{Introduction}

For many academics, supervising higher degree research (HDR) students is expected once they complete their own doctoral research degrees. This expectation arises because successful supervisions are an integral part of their ability to meet promotion criteria, and impact upon their reputation within their own academic faculty, their institution and the wider academic community. Research and research supervision is still seen as superior to teaching and learning in many traditional academic circles. As such, the desire to supervise is high, but their understanding and expertise of the process remains low. Most new supervisors have few or no pedagogic models to draw on other than their own experiences of being supervised (Bøgelund, 2015) and whether they choose to replicate their experience or do the opposite. Increasingly institutions are providing HDR supervision training, but much of this training focusses on compliance issues and degree processes, and not on developing a supervisor pedagogy (Crane et al., 2016).

For the University, the completion of research degrees is an integral part of their identity and is indeed a requirement of their registration and self-accrediting status. There is also funding to be acquired through research output and outcomes, and higher degree completions. Rankings and league tables also draw on research outputs and outcomes as a source for comparison, and they in turn are taken as inferences of quality when judgements are made in subsequent funding rounds and attracting students. While it would be remiss not to note that institutional policies and practices are in a large part in response to these broader, macro issues, this paper focusses on the micro responses to these issues and how they are played out as a power game within the institution in relation to the $\mathrm{PhD}$ students and their supervisors.

This paper looks at how the supervision process is experienced by $\mathrm{PhD}$ students, drawing on the lived experience data from PhD students collected itself as part of a $\mathrm{PhD}$ research project. Core to the findings and interpretation was the issue of power and how institutional influences can distort the power relationship between supervisor and supervisee. French and Raven's (1959) 
bases of social power is used as a lens for exploring these power issues. The aim of this paper is to focus on the participants' supervision narratives and explore the impact of power within this relationship, the institutional influence upon this, and ultimately the implications for the quality of the doctoral outcome.

\section{Literature}

All literature published on the $\mathrm{PhD}$ student supervisor relationship concludes that the $\mathrm{PhD}$ supervisor student relationship has a direct impact on the quality of the $\mathrm{PhD}$ experience and outcomes, with effective supervision being a contributing factor to successful and timely completions (see for example Green and Bowden 2012). It is not surprising given the importance of the relationship that considerable attention has been paid to different models of supervision (Pearson \& Brew, 2002; Hemer, 2012) and the practice of supervision. Supervision is a complex and sometimes problematic relationship, which Lee and Green (2009:617) argue that a specific supervision pedagogy that needs to be flexible and 'optimally responsive to the changing dynamics of candidature and research practice'. From this pedagogical perspective, being a successful academic does not equate to being an effective supervisor. Nevertheless, the supervisor as holder of research and disciplinary knowledge is expected to guide the student in their own process of developing new knowledge and becoming an independent researcher (Kiley, 2009). It is a complex task that challenges many supervisors and can be a process fraught with the supervisors own insecurities and anxieties (Blass, Jasman and Levy, 2012).

In practice, however, supervision is also based on and influenced by institution-specific, discipline-specific and project-specific requirements as well as the expectations and perceptions of the supervisor (Becher \& Trowler, 2001; Bøgelund, 2015; Grant, Hackney and Edgar, 2014). These influences create a tension for both the supervisor and the student to make the relationship work. Institutional and discipline requirements that have a direct impact on supervision include academic workloads, research output expectations and completion times, which are usually tied to funding and promotion models. Given these tensions, the relationship requires careful selection of partners in the process, where inherent responsibilities and power are clearly negotiated and recognised (Neumann 2003; Pyhältö Vekkaila and Keskinen, 2015). Apart from research related compatibility, for example, the research topic and methodology, the relationship requires trust, open communication and needs to consider individual traits including culture, age, gender and even class (Neumann, 2003) because these can lead to mismatches which can result in a very difficult relationship (Carter, Blumenstein and Cook, 2012).

The supervisor and supervisee relationship is idiosyncratic and distinctive, and it changes and evolves as the developing researcher's student identity and self-efficacy shifts from 'becoming' to 'being' an independent researcher (Jazvac-Martek 2009). In conceptualising the supervision relationship, Lee and Green (2009: 626) noted that supervision brings overtones of 'overseeing' and looking over "the production and development of academic knowledge" and identity. Gardner (2010) notes that process of supervision has connotations of power and power differentials - of those who have and those who have not. The supervisor is both the holder and broker of discipline knowledge, and institutional gatekeeper, and has an impact on the students' ability to transition towards successful completion (Lee, 2009). Although this power is not always explicit, it is nevertheless present and facilitated by institutional policies and expectations and support, what French and Raven (1959) identify as reward, coercive, legitimate, referent and expert power over the student.

Hopwood (2010: 105) defined the $\mathrm{PhD}$ as "infused with power, desire and tensions, constructed and contested" as students struggle to exert their agency within these institutional confines that can leave them feeling incapable of reporting difficulties because they feel inferior (Jazvak-Martek, 2009b) and fear becoming orphaned (Wisker \& Robinson, 2012) or exposed as unworthy (Woolderink et al., 2015). Segarra (2016) reflects on the pressure to publish from day one of her doctoral studies, and how this led to feelings of inadequacy, social isolation, and an immense pressure that left her (?) feeling vulnerable through mental exhaustion that was unproductive and arguably unnecessary. In her account of her experience, a senior professor in the field offered to support students in getting publications ready with the 'generous offer' extending to him being named as first author.

From an institutional perspective, there has been a shift away from the pursuit of knowledge to the production of economically viable outcomes as the forces of neo-liberalism 'vanquishes older imaginaries, the university and hence the professoriate are ever more pressured to justify their existence not via recourse to the tattered ideals of self-cultivation, citizenship, or the progress of civilization, but via an appeal to their efficient contribution to goods framed exclusively in economistic terms' (Kaufman-Osborne, 2017, p.110). In many ways, institutions are responding to the government agendas that set the funding mechanisms on which they survive. As the drive to be a 'knowledge economy' underpins most economic growth models, research funding is being focussed on areas where there are tangible and practical outcomes for implementation, such as in the sciences, and the social sciences are losing importance as areas for exploration (Pheonix, 2009).

Applying the French and Raven (1959), power sources, the $\mathrm{PhD}$ supervisor-supervisee relationship can be mapped as follows: 


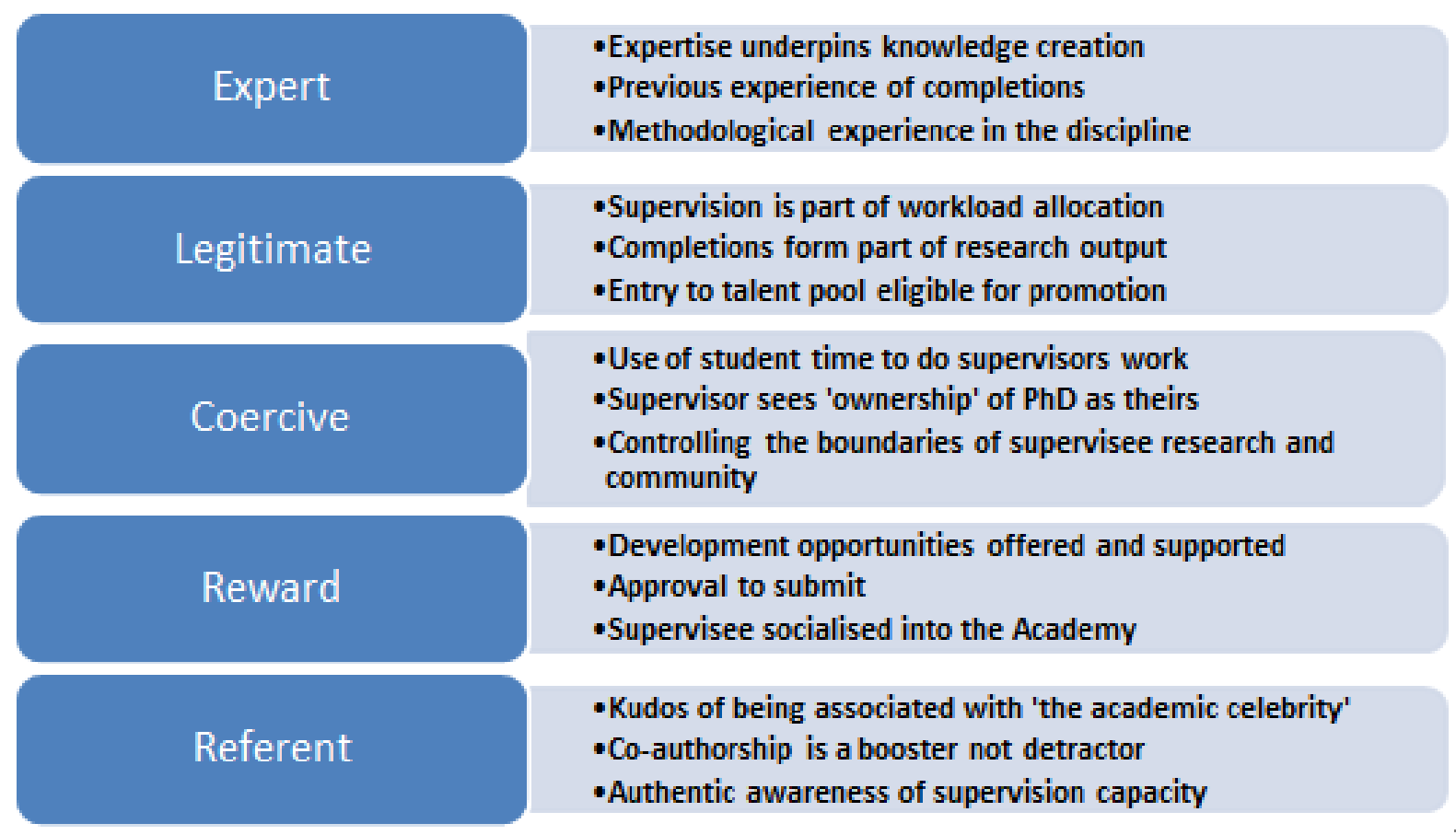

Figure 1. Supervisor-supervisee relationship mapped to French and Raven (1959) Bases of Social Power

Figure 1 summarizes the nature of the supervision relationship as currently evidenced in the literature. The expert and legitimate power bases are expected. Some candidates have a supervisor with referent power which can further tip the balance between coercive and reward bases more towards the coercive as the candidate feels a sense of obligation to yield to the referent power. Coercive and reward power are opposite ends of a see-saw as the same activity can be undertaken from either base of power. For example, helping a candidate write a conference paper for the candidate to deliver is utilizing a reward power base; putting the supervisors name on it and giving it a slant that suits the supervisor is coercive. The element deficient in the literature that became evident in the narratives is the impact of the institution and institutional practices on the academic supervisor, and how these play out in the utilization of power on and over the candidate.

\section{Methodology}

The aim of the $\mathrm{PhD}$ research from which this paper is drawn was to develop a participant-driven theory of the lived experience of being a $\mathrm{PhD}$ student. This was done by analyzing the reported experiences of $23 \mathrm{PhD}$ students from a variety of Australian universities, all doing traditional $\mathrm{PhDs}$ with no taught element, in various disciplines and stages of their $\mathrm{PhD}$, over a period of 12 months. Participants were given the freedom to choose and prioritize the experiences to report on and how they reported on them. Methods included regular emails, blog posting, diaries and Skype interviews and participants selected the method that worked best for them for regular fortnightly or monthly reporting. One of the values of this research lies in what it can tell us are not only about a cohort of PhD students' perceptions of their experiences but also about how the methodology adopted enabled that cohort to choose how to report on those experiences. Not focusing on predetermined elements of the $\mathrm{PhD}$ experience, the methodology used in this research enabled the participants to choose whichever elements of their $\mathrm{PhD}$ experience they wished to discuss freely and without constraint.

A thematic analysis of the data was used to identify the kinds of things $\mathrm{PhD}$ students chose to report on. Interestingly, discussions were rarely, if ever, about doing the $\mathrm{PhD}$ research itself unless there was some breakthrough or setback. Participants reported on their experience of being a $\mathrm{PhD}$ researcher. 'Being' involved processes in which they engaged, their forward momentum and progress, being in a liminal space, their relationships with others and their planned and actual activities they engaged with to make sense of their research. A good deal of the reporting consisted of meaning-making activities to grapple with and make sense of the $\mathrm{PhD}$ phenomena and the actions and behaviours required to progress their $\mathrm{PhD}$ research to completion. Supervision and the experience of being supervised was a key theme in the narratives.

This research did not deliberately set out to research supervision experiences considering the volume of existing literature on supervisor-related research. However, given the number of times that supervision was mentioned in participants' narratives, it would have been remiss not to discuss and include this significant element of the lived 
experience. A thematic analysis of the supervision narratives highlighted that a perceived lack of clear expectations of supervision boundaries led many participants to report experiencing uncertainty about the relationship, the task and their sense of belonging. Power and the sense of power imbalance impacted their relationship with their supervisor and ultimately their progress and sense of belonging.

Post the successful completion of the $\mathrm{PhD}$, the candidate is now in a position to start supervising $\mathrm{PhD}$ students. This shift in status has brought to the fore the power imbalance that the research highlighted exists in the respective roles of the student/supervisor and that relationship. Reflecting on this with her own supervisor, made explicit the tacit expectations that institutional policies and processes impose on the role of the supervisor and the relationship, and this realisation drove the authorship of this paper. French and Raven's (1959) model has provided a theoretical framework to closer examine this phenomenon.

\section{Findings}

Reanalysing the participants' supervision narratives highlighted how the supervisor expert and referential power impacted the students lived $\mathrm{PhD}$ experience. Supervision-related narratives focussed on how to retain a good working relationship and how to avoid negative encounters that could potentially jeopardise their $\mathrm{PhD}$ and future outcomes. The main themes identified in these power narratives are related to role clarity, time, finding voice and securing their future. Students wanted a Supervisor who was an expert in their field to guide them to develop new knowledge and become an independent researcher - maybe even become the expert as their supervisor was.

'I have a suitable supervisor in my discipline. He's not only an expert in the technical but also he knows what's going on in (in my field). When we talk...I am so happy that he knows what's going on.'

\subsection{Role Clarity}

Role clarity refers to uncertainty about the expectations of being a $\mathrm{PhD}$ student and the responsibility of the supervisor. Students expected to be challenged but also expected to be supported, and to be led by a supervisor with expertise in their field of research or methodology. Many were initially awestruck and even fearful of their supervisors' seniority and felt a definite power structure.

II think I like both my supervisors. I think there are certain expectations I really struggled with such as what was expected of me as a PhD student and what they wanted. I'm sort of getting it but there's definitely a power structure there'.

Some reported little contact with their supervisors, and others reported that they were not treated like students but treated as an employee working on one of their supervisor's projects. Often the responsibilities of the second supervisor, sometimes referred to as the associate supervisor, remained a mystery and a source of frustration whereas for others the second supervisor became their guide.

'My co-supervisor who is based elsewhere is itinerant and ephemeral and this is a source of frustration in terms of organising supervision and getting little feedback...hence not sure if they have been read - a concern when I am submitting for publication under not just my name but both supervisors as well.'

'My first supervisor had this opinion about the students that they are slaves that they have to work to make papers for the supervisor. While my second supervisor, who is now my main supervisor, he thinks that PhD students are apprentices who are here to learn to do research and we are supposed to teach them. So had a better attitude and I like that attitude. So I chose to work with him.'

Role clarity also extended to what the role the student was in the supervisor/supervisee relationship. Was the supervisee responsible for supporting the supervisor or was the supervisor responsible for supporting and guiding the supervisee.

I I am also extremely concerned about when I can start to write up my thesis and how long it will take me to complete it. Without fixing up the two papers, my supervisors seem to have no interest in discussing the thesis with me.'

\subsection{Time}

'It's annoying that I make an appointment with my supervisor-I'm on time and he's late and then he shows up an hour and a half later and it's wow 'yes, I'll talk to you now'. Or you send an email and you don't get a reply for 2 weeks - I say that's really annoying.'

Having time with their supervisor was another key theme. It was understood that their supervisors had full workloads including supervising other students, researching and teaching. Participants with senior supervisors experienced less time with their supervisors. These participants soon came to realise that they held ambitious expectations of their supervisor to have time to read their work before a meeting, respond to emails and have regular meetings. While this was annoying, it also curtailed their ability to progress their research unless they fitted in with the needs and demands of their supervisor. Participants deliberately made no note of the lack of guidance and support they were receiving from their supervisors in their progress reports. Noting instead their lack of progress for personal reasons so as not to offend the supervisor and get them off-side.

'They have so much teaching load. I don't get even an 
hour a week to see them - but they have to look at this because it is totally technical and nobody else is going to get this. He has to read it and he has to let me know if it's telling the reader what I'm thinking it's going to tell. I need him to put time (in) and read it.'

'I just want to gag that I am signing this. I feel that it is unfair to make me sign this. I haven't had written feedback. I haven't had written guidance on what I am supposed to do. And I do have a lot of other concerns?? But, AS IF, I would put them in a letter and risk totally getting my supervisors off-side? I feel trapped by this.'

It should be noted that a minority of the participants' narratives, even those with senior professors, did not reflect time poor supervision or a lack of support in their own research even if it did not directly benefit the supervisor. This minority reported having experienced and acclaimed expert supervisors who provided them with timely feedback and support, and did not place undue pressure on them to publish with the supervisor or research in the supervisor's preferred area of research.

'I am positively surprised that he has so much time for me and my project. I did not expect that. He is a very busy professor and has lots of things going on. I expected to be pretty much left alone here - maybe not to get disappointed. We have weekly meetings. He has put me in contact with his colleagues and they are helping me with so much I'm surprised by that -people are willing to give their time to a project that is not really going to benefit them.'

\subsection{Finding Voice}

As students progressed their own research, they started finding their own voice and opinion about the direction and purpose of their research. For some, finding their voice was another troubling experience because this means they will gradually disentangle their research from their supervisor, seeking out others and having an opinion that might differ from that of their supervisor. Considerable time was spent reflecting on the way they have an opinion or voice of their own could be exercised tactfully and in a way not to offend their supervisor. An interesting finding was that those who had previously sought out others, such as mentors, with or without their supervisor's knowledge, and had their own ideas legitimised were more successful in voicing their own ideas and opinions.

'I've started to think a little more independently of him. I still think that as far as guiding me through the process and taking his direction or taking his suggestions on board - is still a good tactic. But actually yesterday, for the first time I kind of - he suggested one thing - and I said 'well no, I would really like to try this out first'. I don't think I've ever said 'no' to him about what he's suggested.' (AM)

Whereas participants who had worked very closely usually with one supervisor only found expressing their own voice and becoming independent more challenging. Some participants reported how their supervisor had nurtured and mentored to the extent that it was almost 'umbilical' and they need to struggled to find their independence and voice.

'If you look at my CV everything has her name on it. I have not done one thing without her.... I don't feel the power to say I disagree with that comment or I don't want to take that on-board.'

\subsection{Securing the Future}

'I don't want him to become angry as I need his support in future as a referee...'

Having the support of the supervisor is critical to get the thesis completed and signed-off. For those participants who wanted to secure a role in academia they need their supervisors further support to secure their future by establishing contacts, publications and getting a reference.

'Sleepless night complete with waking rants in my head about how to respond to ex-co-supervisor. Woke up at 4 am with the realisation that I need a reference from this man. ALL the feminist fibres in my body want to reject this necessity. All the pragmatic thoughts in my head tell me that this contact with him can soon be over. Just get the reference.'

The findings indicate that institutional priorities and academic workloads impacted on the supervision practice and the lived experiences of most of the $\mathrm{PhD}$ student participants in this research.

\section{The Researcher's Experience}

My own experience of being supervised differed from most of the research participants. With an external supervisor who was not under institutional pressure to perform, I was not expected to support another person's research interests or to publish outside the realms of what I was doing when I was ready to. I successfully completed my $\mathrm{PhD}$ within the institutional set timeframe while working full-time. Being externally supervised provided a cloak of invisibility removing some of the pressures of the institution, but it also meant I did not receive the perks attributed to a supervisor's power or kudos in the institution which will contribute to my academic career, nor was I exposed to opportunities to collaborate with others and be introduced into the academy. With the growing number of $\mathrm{PhD}$ students and reduced number of tenured academic positions, I do note this may disadvantage me in the longer term.

Now on completion of my own $\mathrm{PhD}$, I am also expected, while juggling teaching and administrative duties, to regularly produce papers, research output and secure research funding to maintain my academic currency and be 
considered for promotion review. Given my knowledge of the lived $\mathrm{PhD}$ supervision experience and my own somewhat different experience, I now face the quandary: have I become an academic that understands the impact that supervision has on students and have I used legitimate power in my supervision practice and potentially reduce my chances for academic promotion? Or, do I succumb to these institutional pressures to recruit $\mathrm{PhD}$ students and use my $\mathrm{PhD}$ students to support my research interest, and my ongoing production of papers and research output?

The impact of power on the supervision relationship and the students' experience is clear in the participants' narratives. Participants were well aware of the supervisors' authority and how this power could impact their $\mathrm{PhD}$ success or otherwise. Supervision-related narratives focussed on how to retain a good working relationship and how to avoid negative encounters that could potentially jeopardise their $\mathrm{PhD}$ and future outcomes. The main themes identified in these power narratives are related to role clarity, time, finding voice and securing their future. In exploring these themes further, it also became evident that students' perceptions of the $\mathrm{PhD}$ and being supervised had a significant influence, particularly early in their students $\mathrm{PhD}$ journey, on the supervisor's embodiment of power in their experience. The culmination of these findings has led us to re-envision French and Raven's (1959) Bases of Social Power with the supervisors' referent and expert power shifting along a continuum from legitimate to coercive with the additional element of 'neglect'. Neglect is the outcome of workload and research output models or manifested when the student is perceived as not up to the task or unwilling to contribute to the supervisors' production of research output.

\section{Expert/Referent}

Referent/Expert

\section{Legitimate + Reward - $\quad$ Coercive}

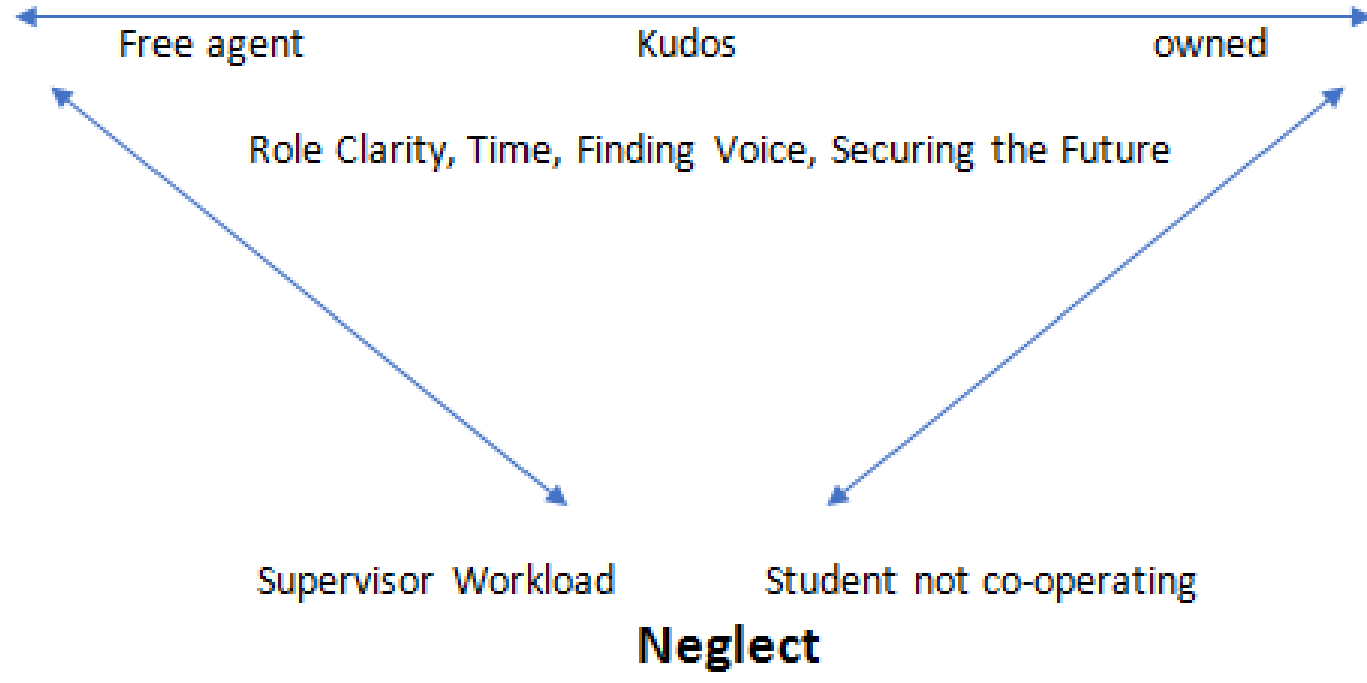

Figure 2. Embodiment of power on the students lived experience 


\section{Role of the Institution}

Reflecting on the student-supervisor power relationship and its embodiment within the students' lived experience, the silent influence that is alluded to but not directly referred to is that of the institution. This may be because the students are unaware of the institutional impact on supervisors, or it may have been too removed for them to name or identify. One really has to be within the Ivory Tower to understand how the circular staircase works.

Considering the application of French and Raven's sources of power from the perspective of 'the Institution', there is a direct challenge to the 'ideal' of the university, with the notions of academic freedom, liberal study for the sake of education, and the self-governing nature of the idea of the university. While the Ivory Tower of the university used to be the symbol of freedom of thought, expression and (within some ethical limitations) experimentation to discover the new - in its more idealistic terms - the Ivory Tower now represents Jeremy Bantham's late $18^{\text {th }}$ century idea of Panopticon, an institutional building in which one watchman can view any person at any time, and the mere fact that you could be being watched is enough to support self-regulation of activity.

Foucault developed the idea of the panopticism further, seeing visibility as a trap. With regards to $\mathrm{PhD}$ students, this includes being visible and presenting at internal research presentation opportunities, publishing in suitable journals, building the requisite networks required for career progression, supporting their supervisors in their research rather than their own research, and in essentially adhering to rather than challenging the institutional norms.

Prasad (2016) notes that the mere assumption of being under the gaze of authority, through self-reporting and informal but public scrutiny (such as in the staff room), provides the necessary impetus for $\mathrm{PhD}$ students to conform to prescribed and (self-) disciplined behaviour in their institutions. This includes conforming to the 'requirement' to publish in suitably ranked journals to meet the institution's needs, rather than publishing to the audience most appropriate to the research or researcher. The author asserts:

I felt compelled to write on topics that were more mainstream, that is, on topics that occupied the pages of the recent issues of the field's elite journals. This predicament was engendered by the fact that there were competing interests that were influencing my research agenda. On the one hand, I was cognizant of the research questions that I wanted to ask and the research approach that I wanted to adopt but, on the other, I was desperate to feel that I was a successful member of my institution and of the wider academy (ibid: 79).

Segarra (2016) reflects on the pressure to publish from the first day of her doctoral studies, and questions how success is defined in her doctoral studies, and asks whether getting a long list of publications with no real novel ideas is the aim. There appears to be a resigned tone of defeat in her reflection of her doctoral experience, where she has acquiesced for academic and institutional acceptance but has lost her sense of self-identity and value in doing so.

This institutional pressure to adhere to the mainstream is further underpinned by the workings of the Universities ethics committees, which is a panel of 'ethical experts' who can compound the ethical issues rather than resolve them to the point that certain methodologies, approaches and areas of research are deemed too problematic to even consider tackling (Pheonix, 2009). As such, they have often become the institutional embodiment of the removal of academic freedom. That is not to say that unethical research should be allowed, but the boundaries of what is and is not deemed ethical is not up for debate.

The extent to which ethics and academic freedom are driven by economics is also questionable. Kaufman-Osborne's (2017) neo-liberal interpretation views the shift in institutional behaviour away from the pursuit of knowledge to the production of economically viable outcomes as contextual positioning of the university within a changing culture and society, and a shifting economic model, which explains, if not offers a justification, for the changing employment practices that threaten academic freedom and lead to academic performativity.

But even for those whose performativity is the norm, the doctoral process cannot be managed in the same vein. For example, MacNeil (2016) embarked on his doctoral studies as an expert time and project manager, armed with Gantt charts and all the tools necessary to meet the institutional outcomes ahead of schedule, if not on time. He was the model of performativity. However, he soon hit a glitch.

The "output of a doctoral student (indeed, the output of many knowledge workers) is thinking. The faulty tools of industrial management become even less effective when the work simply cannot happen in a linear, assembly line fashion. Despite my frustrated attempts, my best ideas simply cannot be scheduled (ibid: 103).

MacNeil reflects on the process of rehumanising his $\mathrm{PhD}$ experience to recover meaning and purpose from it, so it becomes a 'tool' for his future rather than his definition of being, and as a result, it reframes the institutional pressures and timeframes that drive his behaviours within the program.

In many ways, institutions are responding to the government agendas that set the funding mechanisms on which they survive. As the drive to be a 'knowledge economy' underpins most economic growth models, research funding is being focussed on areas where there are tangible and practical outcomes for implementation, such as in the sciences, and the social sciences are losing importance as areas for exploration (Pheonix, 2009).

Finkelstein et al. (2015) question the role and quality of $\mathrm{PhD}$ provisions in their ability to produce the next necessary generation of academics needed globally. They 
question the extent to which there is a focus on thesis preparation rather than more general academic development, and whether every $\mathrm{PhD}$ has good career preparation for entry level academic roles. The tendency for in-breeding (hiring graduates from their own institution) manages the supply of candidates somewhat, and ensures an institutional cultural norm is sustained.

For international students, there are even more institutional factors at play. Fotovatian and Miller (2014) found that for international students, their motivation behind their studies impacted greatly on their institutional conformity and experience. While all international students were labelled with the same 'stereotype' (to get residency) which they had to fight to establish an individual identity, the importance of establishing an individual identity was less important to students seeking to return to their home country on graduation than for those wishing to remain in Australia for their academic careers. For those wishing to stay, conforming to the cultural performativity norm was seen as an essential career tactic for survival.

Recruitment practices and human resource management (HRM) also have an impact on supervisors' behavior, and the students. Altbach (2015) notes the practice of 'in-breeding' in what he estimates to be $50 \%$ of academic career positions. This is when the institution hires home-grown graduates to fill vacant positions, which he notes is detrimental to a dynamic academic profession and such closing of academic markets makes young academics dependent on their senior colleagues and the institutions good will, limiting ideas and challenges and driving conformity to an institutional norm. While staying in the good books might not be a phenomenon limited to academia, and arguably occurs in all large institutions, most other institutions do not promote the ideal of free or liberal thought as a raison d'etre.

The institutional power sources that play on the $\mathrm{PhD}$ candidate can be summarised in figure 1 and stem from all of the social power bases noted by French and Raven, but are enacted through different 'actors' in the institutional process (in brackets in the diagram). Note while some of these are enacted through the supervisor, it is the institutions framing of the supervisor role that allows these to occur in this instance, rather than the personality of the supervisor themselves, and hence they are an agent of the institution here, rather than an agent in themselves.

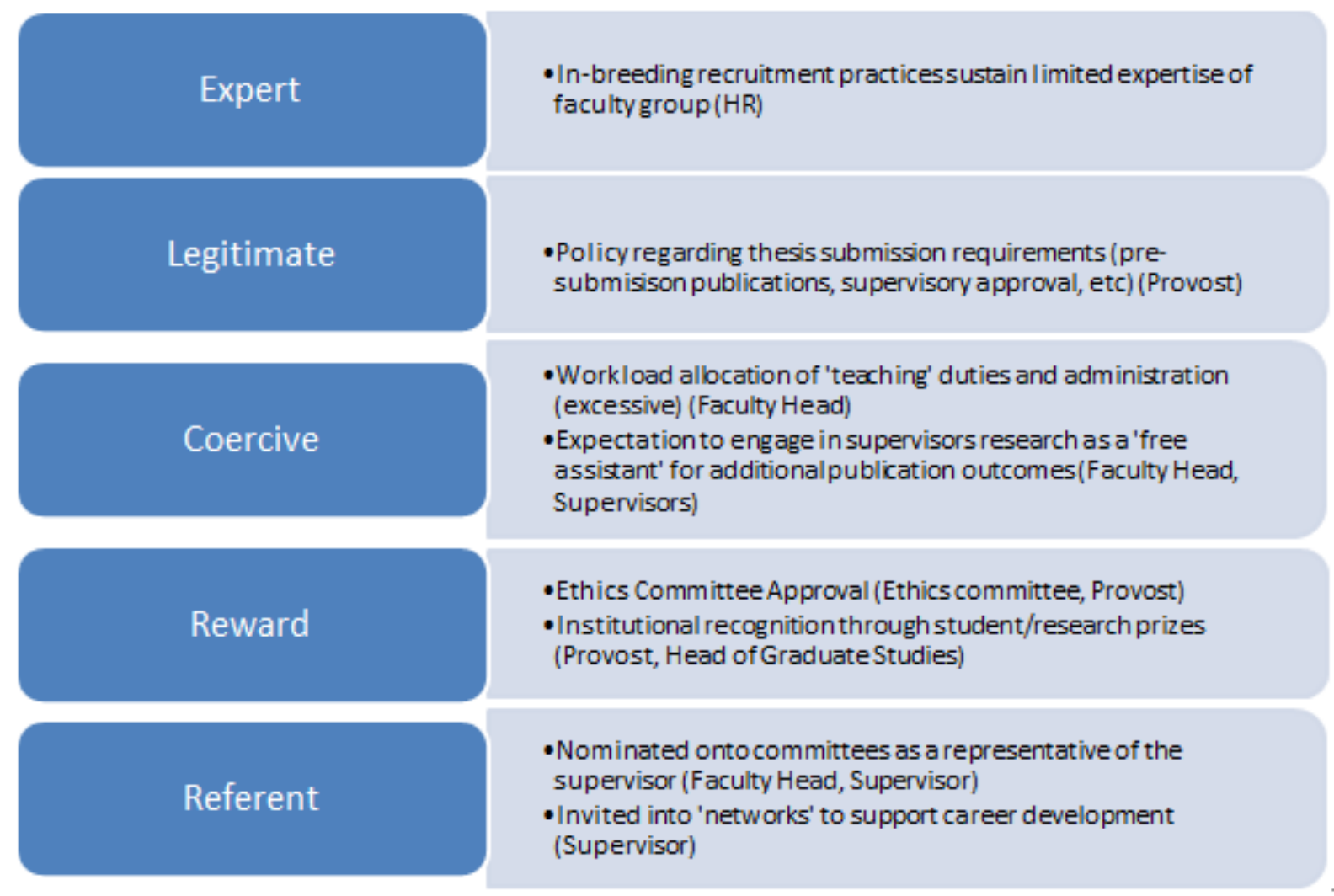

Figure 3. Institutional Embodiment of French and Raven's (1959) Bases of Social Power 


\section{Conclusions}

The power relationship between supervisors and their students can, in many cases, be named 'abusive' and at best is one which places the student in an incredibly vulnerable position. This is legitimised and supported by the institution and its practice, whether intentional or not, and in order to see any future within the academic world or successfully completing their $\mathrm{PhD}$, reporting the abuse is not an option. Hence, it will not matter how many reports, interviews or check-ins the institution requires, the abuse will remain hidden, mirroring much of what happens generally in society. So how can the power imbalance be redressed? A key factor should be the introduction of someone external to the institution who is not bound by the institutional pressures to perform. This may be achieved by introducing retired Professors to the team or supervisors from industry (see Recommendation 6 of the Australian Council of Learned Academies 2016 Final Report (McGagh et al. 2016)) - people who are supervising because they are interested in the student and the research but have no pressure to meet the institutions' performativity criteria. They should be paid for this role as it is time consuming and is of no benefit to them, and it saves the institution workload hours so is simply a reallocation of funds. Paying external supervisors means they treat it as a professional engagement rather than a favour, and holds them to account if they are not available to the student or meeting their needs. It does not hold them to the research performance incentives that apply to internal supervisors, and does not impact their future career. Finally, there needs to be closer monitoring and evaluation of supervisors' performance (McGagh et al., 2016), not in terms of rewarding supervisors because of research output alone, but in terms increased investment and structural support that recognises, rewards and celebrates best practice supervisors.

\section{REFERENCES}

[1] Altbach, P.G. (2015) Building an Academic Career: A $21^{\text {st }}$ Century Challenge. In Yudkevich, M., Altbach, P. G., \& Rumbley, L. E. (Eds) Young Faculty in the $21^{\text {st }}$ Century: An International Perspective. State of New York Press.

[2] Becher, T., \& Trowler, P. R. (2001). Academic tribes and territories: Intellectual enquiry and the culture of disciplines (2nd ed.). Buckingham, UK: SRHE \& Open University Press.

[3] Blass, E., Jasman, A., \& Levy, R. (2012). Supervisor reflections on developing doctoralness in practice-based doctoral students. Quality Assurance in Education, 20(1), $31-41$.

[4] Bøgelund, P. (2015) How Supervisors perceive PhD Supervision. International Journal of Doctoral Studies, 10 ,
$39-55$.

[5] Carter, S., Blumenstein, M., \& Cook, C. (2012). Different for women? The challenges of doctoral studies. Teaching in Higher Education, 18(4), 339-351.

[6] Crane, L., Kinash, S., Bannatyne, A., Judd, M. M., Eckersley, B., Hamlin, G., ... \& Stark, A. (2016). Engaging postgraduate students and supporting higher education to enhance the 21 st century student experience.

[7] Finkelstein, M. J., Iglesias, K. W., Panova, A., \& Yudkevich, M. (2015) Future Prospects for Young Faculty Across the Academic World A Global Comparison and assessment. In Yudkevich, M., Altbach, P. G., \& Rumbley, L. E. (Eds) Young Faculty in the $21^{\text {st }}$ Century: An International Perspective. State of New York Press.

[8] Fotovatian, S. \& Miller, J. (2014) Constructing an institutional identity in university tea rooms: the international $\mathrm{PhD}$ student experience, Higher Education Research \& Development, 33:2, 286-297

[9] French, J. R., Raven, B., \& Cartwright, D. (1959). The bases of social power. Classics of organization theory, 7, 311-320.

[10] Gardner, S. K. (2010). Faculty perspectives on doctoral student socialization in five disciplines. International Journal of Doctoral Studies, 5, 39-53.

[11] Grant, K., Hackney, R., \& Edgar, D. (2014). Postgraduate research supervision: An 'agreed' conceptual view of good practice through derived metaphors. International Journal of Doctoral Studies, 9, 43-60.

[12] Green, P., \& Bowden, J. (2012). Completion mindsets and contexts in doctoral supervision. Quality Assurance in Education, 20(1), 66-80.

[13] Hemer, S. R. (2012). Informality, power and relationships in postgraduate supervision: Supervising $\mathrm{PhD}$ candidates over coffee. Higher Education Research \& Development, 31(6), 827-839.

[14] Hopwood, N. (2010). Doctoral experience and learning from a sociocultural perspective. Studies in Higher Education, 35(7), 829-843.

[15] Jazvac-Martek, M. (2009). Emerging academic identities: How education $\mathrm{PhD}$ students experience the doctorate. Unpublished doctoral dissertation, McGill University, Montreal.

[16] Jazvac-Martek, M. (2009b). Oscillating role identities: the academic experiences of education doctoral students. Innovations in Education and Teaching International, 46(3), 253-264.

[17] Kaufman-Osborne, T (2017) Disenchanted Professionals: The Politics of Faculty Governance in the Neoliberal Academy. Perspectives on Politics, 15, 1. 100-117.

[18] Kiley, M. (2009). Identifying threshold concepts and proposing strategies to support doctoral candidates. Innovations in Education and Teaching International, 46(3), 293-304.

[19] Lee, A. (2009). Some implications of European initiatives for doctoral supervision. In E. Froment, J. Kohler, L. Purser, \& L. Wilson (Eds.), EUA Bologna handbook: Making 
Bologna work (pp.). Berlin: Raabe.

[20] Lee, A., \& Green, B. (2009). Supervision as metaphor. Studies in Higher Education, 34(6), 615-630.

[21] MacNeil, R. (2016) Being a Productive PhD Student (While Cursing Scientific Management, the "Spirit of Capitalism," and My Addiction to Realism). In Prasad, A (Ed) Contesting Institutional Hegemony in Today's Business Schools: Doctoral Students Speak Out. Emerald Publishing Group. Ch 7.

[22] McGagh, J., Marsh, H., Western, M., Thomas, P., Hastings, A., Mihailova, M. and Wenham, M. (2016) Review of Australia's Research Training System.

[23] Neumann, R. (2003). The doctoral education experience: Diversity and complexity. Canberra, Australia: Department of Education, Science and Training, Commonwealth of Australia. Retrieved from http://hdl.handle.net/1959.14/10 88011

[24] Pearson, M. and Brew, A. (2002). Research Training and Supervision Development. Studies in Higher Education 27(2), 135-150

[25] Pheonix, A. (2009) Enabling Research? Silencing and recognition in social research. In Satterthwaite, J., Piper, H., \& Sikes, P. (Eds) Power in the Academy. Institute of Education Press.

[26] Prasad, A. (2016) Playing the Game and Trying Not to Lose Myself: A Doctoral Student's Perspective on the Institutional Pressures for Research Output. In Prasad, A (Ed) Contesting Institutional Hegemony in Today's Business Schools: Doctoral Students Speak Out. Emerald Publishing Group. Ch 5.

[27] Pyhältö, K., Vekkaila J., \& Keskinen J. (2015). Fit matters in the supervisory relationship: Doctoral students and supervisors perceptions about the supervisory activities. Innovations in Education and Teaching International, 52(1), 4-16.

[28] Segarra, P. (2016) Quantity versus Quality: The Publication Quagmire. In Prasad, A (Ed) Contesting Institutional Hegemony in Today's Business Schools: Doctoral Students Speak Out. Emerald Publishing Group. Ch 6.

[29] Wisker, G., \& Robinson, G. (2012). Picking up the pieces: Supervisors and doctoral 'orphans'. International Journal for Researcher Development, 3(2), 139-153.

[30] Woolderink, M., Putnik, K., van der Boom, H., \& Klabbers, G. (2015). The voice of $\mathrm{PhD}$ candidates and $\mathrm{PhD}$ supervisors. A qualitative exploratory study amongst $\mathrm{PhD}$ candidates and supervisors to evaluate the relational aspects of $\mathrm{PhD}$ supervision in the Netherlands. International Journal of Doctoral Studies, 10, 217-235. 